March 2005

\title{
Psychomotor skills for the undergraduate medical curriculum in a developing country--Pakistan
}

\author{
Rashida Ahmed \\ Aga Khan University, rashida.ahmed@aku.edu \\ Zoon Naqvi \\ Aga Khan University \\ Ineke Wolfhagen
}

Follow this and additional works at: https://ecommons.aku.edu/ pakistan_fhs_mc_pathol_microbiol

Part of the Microbiology Commons, and the Pathology Commons

\section{Recommended Citation}

Ahmed, R., Naqvi, Z., Wolfhagen, I. (2005). Psychomotor skills for the undergraduate medical curriculum in a developing country-Pakistan. Education for Health, 18(1).

Available at: https://ecommons.aku.edu/pakistan_fhs_mc_pathol_microbiol/967 


\title{
Psychomotor Skills for the Undergraduate Medical Curriculum in a Developing Country-Pakistan
}

\author{
RASHIDA AHMED ${ }^{1}$, ZOON NAQVI $^{1} \&$ INEKE WOLFHAGEN $^{2}$ \\ ${ }^{1}$ Aga Khan University, Karachi, Pakistan, and ${ }^{2}$ Maastricht University, \\ Maastricht, The Netherlands
}

\begin{abstract}
Objective: To identify essential psychomotor skills for all the medical graduates of an undergraduate programme in Pakistan.

Materials and Methods: Twenty-five physicians practising in a tertiary care centre and ninety primary care physicians used a Likert's scale, ranging from "very essential" to "not required at all", to mark 99 psychomotor skills in the undergraduate medical curriculum in Pakistan.

Results: Overall the opinions of both the groups about the essential skills matched except for a few areas.

Conclusion: This study provides baseline data about psychomotor skills that a medical graduate in developing countries should be able to perform. Further studies will be undertaken by involving other stakeholders to identify and incorporate these skills in the undergraduate medical curriculum, thereby enabling graduates to practice in all the settings in Pakistan.

KEYWORDS Undergraduate medical curriculum, essential psychomotor skills, developing country, primary care, tertiary care.
\end{abstract}

\section{Introduction}

Medical curricula need to be defined in accordance to the needs of specific communities (Nooman, 1989). This implies that it would be difficult for any two programmes to be identical, although some features may be common to all. To provide quality health care, a strong knowledge base with development of appropriate skills and behaviours is required. It has been pointed out that delivery and assessment of cognitive, or knowledge domain, should be stressed

Author for correspondence: Dr Rashida Ahmed, Educational Development and Pathology, Faculty of Health Sciences, Aga Khan University, Stadium Road, PO Box 3500, Karachi 74800, Pakistan. Tel: +9221 48594682. Fax: +9221 4934294. E-mail: rashida.ahmed@aku.edu 
$6 \quad R$. Ahmed et al.

in the curriculum and the faculty members should agree upon the mode of delivery (Irby et al., 1991).

Skills and attitude components have recently started receiving such attention in curricula. The concern is growing that the teaching and assessment of clinical skills lacks uniformity and that the skills of the medical graduates are far from expectations of the stake holders (Ringsted et al., 2001).

Different stakeholders need to be involved in identification of core skills and establishing clear objectives. Special consideration must be given to the fact that not all graduates will work in the tertiary care units. In countries like Pakistan, they may be working in a basic health unit as the only health care providers, without any additional training in formal post-graduate programmes. Hence, physicians working in primary care should participate in designing the skills content of undergraduate medical curricula. Identifying such skills (Sturmberg, 1995) and developing guidelines for teaching of clinical skills must be based on balanced evidence of their practical utility and local needs, and not on technophobic prejudices (Woodcock, 1995; Ringsted et al., 2001).

In developing countries, the problem is compounded by economic causes pertaining to patients and limited resources available to the governments to spend on health care. The expectations in such countries should be seen in context of the local problems and available resources. Although there is increasing awareness about the specific and need-based content in the poor countries, very small amount of relevant material appears in the medical literature. The literature search to identify skills in the developing world yields only very occasional papers. For example, a paper from India (David et al., 1997) discusses the technical skills required by the graduates in the developing world in the field of emergency medicine. But nothing comparable to the work of Irby (Irby et al., 1991), which includes a comprehensive list of psychomotor skills, is found from the developing world.

Due to the limited information available in the literature, there appears to be a lack of clarity regarding psychomotor skills in the minds of faculty involved with undergraduate curricula. Although no published data is available, the faculty members in Pakistani medical schools have expressed similar problems during informal discussions with them. Personal and discipline preferences usually determine what the students should be able to do at the end of a particular clinical rotation. The similar lack of clarity was experienced by the author while setting up clinical skills examinations in her parent institution (Aga Khan University, Pakistan).

The task of identifying essential psychomotor skills in the undergraduate curricula was taken as a research project for a master's thesis from Maastricht University, Netherlands. The study was designed to obtain the 
opinions of physicians working in a tertiary care centre and in a primary care setting, regarding essential psychomotor skills in an undergraduate medical curriculum, which would enable the graduates to work in all settings.

\section{Materials and Methods}

A rating scale was developed (with the help of one of the co-authors who supervised a master's thesis from Maastricht University) listing ninety-nine psychomotor skills (Table 1) identified from international literature (Leventhal \& Goodman, 1981; Snow \& Imbembo, 1986; Cheung et al., 1993; Cordeiro et al., 1993; Jansen et al., 2000). Since infections, including tuberculosis, are major ailments in this part of the world, recommendations of World Health Organization (WHO, 1997) were also included in the list. Further additions were made with the help of focus group discussions with AKU faculty members belonging to various educational committees and the Family Medicine faculty. This resulted in further modifications to make it more relevant to Pakistani context. For example, stains for micro-organisms were included in the list of skills, given the high mortality and morbidity due to infections in Pakistan as also mentioned by WHO (World Health Organization, 1997). Respondents were asked to identify how essential they perceived a particular skill for incorporation in undergraduate medical curriculum. The five point Likert's scale, ranging from "essential", "important but not essential", "not sure", "nice to know" and "not required at all" was used. "Essential" was defined as a must pass skill.

The participants for the study were derived from two different groups. Twenty-five clinical faculty members of Aga Khan University Medical College (AKUMC) were included in the first group. The group was comprised of faculty members involved in various educational committees for the undergraduate medical education either as chairs, members or examination coordinators. They were contacted on a one-to-one basis and were given the background for the questionnaire. Once they agreed, they were sent the questionnaire for rating along with a written preamble about the purpose of the study and instructions on filling out the questionnaire.

The second group was composed of ninety general practitioners serving in the community. This group included participants of the Continuing Medical Education (CME) programme run by the AKU and self-selected general practitioners. The non-AKU group was a diverse group comprised of physicians with experience ranging from 1-25 years in different communities from different economic strata. The questionnaire was distributed in the monthly Continuing Medical Education seminar and to the self-selected group of general practitioners in the community (convenience sample) after 
$8 \quad R$. Ahmed et al.

Table 1. Opinions about Essentiality of Skills marked by both the groups with statistical differences (Significant differences are marked by asterisks*)

\begin{tabular}{lccc}
\hline Skill & AKU $(\%)$ & Non AKU (\%) & Signif \\
\hline & & & \\
Obtain blood samples & 100.0 & 91.2 & 0.15 \\
Intra-muscular injections & 100.0 & 89.3 & 0.11 \\
Nasogastric tube insertion & 100.0 & 86.0 & 0.07 \\
Intra-venous injections & 95.5 & 91.1 & 0.53 \\
Electrocardiography & 95.5 & 89.5 & 0.42 \\
Care of peripheral venous lines & 95.5 & 87.5 & 0.28 \\
Pulse measurement & 95.5 & 94.7 & 0.93 \\
Temperature measurement & 95.5 & 96.5 & 0.80 \\
Intra-dermal injections & 90.9 & 85.7 & 0.55 \\
Subcutaneous injections & 90.9 & 83.9 & 0.42 \\
Insertion of urinary rubber catheter & 90.9 & 91.2 & 1.00 \\
Blood pressure measurement & 90.9 & 94.7 & 0.53 \\
Basic life support & 90.9 & 91.2 & 0.93 \\
Giving oxygen through mask & 90.9 & 89.3 & 0.92 \\
Fundoscopy & 86.4 & 86.0 & 0.91 \\
Nasal speculum examination & 86.4 & 89.3 & 0.70 \\
Insertion of indwelling catheter & 86.4 & 82.5 & 0.65 \\
Hemostasis procedures & 86.4 & 75.4 & 0.27 \\
Dressing in minor burns & 86.4 & 86.0 & 0.93 \\
Preparation of oral rehydration salt & 86.4 & 91.1 & 0.55 \\
Sterile instruments handling & 86.4 & 91.1 & 0.49 \\
Stool occult blood & 86.4 & 71.9 & 0.16 \\
Otoscopy & 81.8 & 87.3 & 0.53 \\
Throat swabs & 81.8 & 77.2 & 0.50 \\
Wound swabs & 81.8 & 70.2 & 0.27 \\
Simple dressing in minor trauma & 81.8 & 89.5 & 0.35 \\
Application of pressure bandage & 81.8 & 83.9 & 0.73 \\
Sponging & 81.8 & 93.0 & 0.12 \\
Advanced life support & 81.8 & 71.4 & 0.32 \\
Perform Mantoux Test & 81.8 & 68.4 & 0.22 \\
Urine dipstick & 81.8 & 80.4 & 0.83 \\
Pulmonary function tests (interpret) & 81.8 & 77.2 & 0.58 \\
Care of the central venous lines & 77.3 & 75.4 & 0.96 \\
Shifting a patient with spinal injury & 77.3 & 75.4 & 0.72 \\
Zeihl Nelson stain (interpret) & 77.3 & 77.2 & 0.93 \\
Peripheral film preparation for & 77.3 & 75.4 & 0.98 \\
malarial parasites & & & \\
Pregnancy test (interpret) & 77.3 & 75.4 & 0.69 \\
Mantoux test (interpret) & 77.3 & 71.9 & 0.45 \\
Care of bedsores & 77.3 & 92.9 & 0.05 \\
Visual field testing & 72.7 & 67.9 & 0.57 \\
Pap smears & 72.7 & 63.2 & 0.30 \\
Ascitic fluid & 72.7 & 73.7 & 0.93 \\
Cerebrospinal fluid from an adult & 72.7 & 73.7 & 0.75 \\
Giving blood transfusions & 72.7 & 91.2 & $0.03 *$ \\
\hline & & & $($ continued \\
overleaf) &
\end{tabular}


Table 1. (continued)

\begin{tabular}{|c|c|c|c|}
\hline$\underline{\text { Skill }}$ & AKU (\%) & Non AKU (\%) & Signif \\
\hline Gram stain (interpret) & 72.7 & 82.5 & 0.31 \\
\hline ESR(interpret) & 72.7 & 80.7 & 0.32 \\
\hline Sterile preoperative preparation & 72.7 & 80.7 & 0.44 \\
\hline Ear swabs & 68.2 & 68.4 & 0.69 \\
\hline Pleural fluid & 68.2 & 68.4 & 0.89 \\
\hline Wound debridement & 68.2 & 84.2 & 0.09 \\
\hline Suturing of clean wound & 68.2 & 86.0 & 0.07 \\
\hline Incision and drainage of an abscess & 68.2 & 89.5 & $0.02 *$ \\
\hline $\begin{array}{l}\text { Preparation of correct strengths of } \\
\text { drugs }\end{array}$ & 68.2 & 82.5 & 0.11 \\
\hline $\begin{array}{l}\text { Peripheral film for malarial parasites } \\
\text { (interpret) }\end{array}$ & 68.2 & 73.7 & 0.50 \\
\hline Urine dipstick (perform) & 68.2 & 75.4 & 0.43 \\
\hline Eye swabs & 63.6 & 62.5 & 0.63 \\
\hline Tracheal intubation & 63.6 & 71.9 & 0.52 \\
\hline Application of external splints & 63.6 & 71.9 & 0.63 \\
\hline Conduct normal vaginal delivery & 63.6 & 68.4 & 0.81 \\
\hline Insertion of airway suctions & 63.6 & 78.9 & 0.23 \\
\hline $\begin{array}{l}\text { Removing foreign body from } \\
\text { external orifices }\end{array}$ & 63.6 & 84.2 & 0.07 \\
\hline Stool occult blood (perform) & 63.6 & 63.2 & 0.92 \\
\hline High vaginal swabs & 59.1 & 59.6 & 0.72 \\
\hline Establishing central venous lines & 59.1 & 80.7 & $0.05 *$ \\
\hline Gram stain (perform) & 59.1 & 75.4 & 0.15 \\
\hline Zeihl Nelson stain (perform) & 59.1 & 73.7 & 0.15 \\
\hline Arterial punctures for blood gases & 54.5 & 71.4 & 0.13 \\
\hline Insertion of chest tubes & 54.5 & 67.9 & 0.24 \\
\hline Skin scrapings & 50.0 & 56.1 & 0.95 \\
\hline Urethral swab & 50.0 & 49.1 & 0.95 \\
\hline Episiotomy & 50.0 & 55.4 & 0.77 \\
\hline ESR(set up) & 50.0 & 78.9 & $0.02 *$ \\
\hline Pregnancy test (perform) & 50.0 & 70.2 & 0.26 \\
\hline $\begin{array}{l}\text { Insertion of intra-uterine } \\
\text { contraception device }\end{array}$ & 50.0 & 52.6 & 0.84 \\
\hline Cerebrospinal fluid from a child & 45.5 & 68.4 & $0.02 *$ \\
\hline Indirect laryngoscopy & 40.9 & 61.4 & 0.12 \\
\hline Cerebrospinal fluid from a neonate & 40.9 & 61.4 & $0.04 *$ \\
\hline Using head mirror & 36.4 & 67.9 & $0.03 *$ \\
\hline $\begin{array}{l}\text { Fine needle aspiration biopsy of } \\
\text { lumps }\end{array}$ & 36.4 & 56.1 & $0.05^{*}$ \\
\hline Joint aspirations & 36.4 & 50.9 & 0.72 \\
\hline Supra pubic cystostomy & 36.4 & 59.6 & 0.11 \\
\hline Intra-ocular pressure & 27.3 & 69.1 & $0.00 *$ \\
\hline Performing venous cut downs & 27.3 & 67.9 & $0.00 *$ \\
\hline Maintenance of ventilators & 27.3 & 58.5 & $0.02 *$ \\
\hline Sigmoidoscopy & 27.3 & 45.6 & 0.26 \\
\hline
\end{tabular}


$10 \quad$ R. Ahmed et al.

Table 1. (continued)

\begin{tabular}{lccc}
\hline Skill & AKU (\%) & Non AKU (\%) & Signif \\
\hline Errors of refraction & 22.7 & 61.8 & $0.00^{*}$ \\
Skin biopsy & 22.7 & 40.4 & 0.26 \\
Pericardial fluid & 18.2 & 43.9 & $0.01^{*}$ \\
Dilation \& evacuation- products of & 18.2 & 55.4 & $0.02^{*}$ \\
conception & & & $000^{*}$ \\
Setting up of ventilators & 18.2 & 66.1 & $000^{*}$ \\
Perform circumcision & 18.2 & 64.9 & $000^{*}$ \\
Dilation \& curettage for endometrial & 13.6 & 48.2 & 0.09 \\
sampling & 13.6 & 35.1 & $0.01^{*}$ \\
Bronchoscopy & 9.1 & 49.1 & $000^{*}$ \\
Direct laryngoscopy & 9.1 & 69.6 & $0.03^{*}$ \\
Intra-thecal injections & 9.1 & 38.6 & $0.01^{*}$ \\
Trucut biopsy of liver & 4.5 & 33.3 & $0.01^{*}$ \\
Trucut biopsy of kidney & 4.5 & 38.6 & $0.01^{*}$ \\
Gastroscopy & 0.0 & 40.4 & $0.05^{*}$ \\
Mucosal biopsy from mouth & 0.0 & 26.8 & \\
Trucut biopsy of lung & & &
\end{tabular}

explaining the purpose of the questionnaire to them. Those who agreed filled out the questionnaires.

The responses were entered in the SPSS 10 version for Windows. For the purpose of analysis, the responses were regrouped into three groups. Scores of 4 and 5 were combined in one group, scores of 2 and 1 were merged to form one group, and a score of 3 (which meant the participant was not sure of the essentiality) was kept separate. The frequencies for the AKU and non-AKU participants were calculated separately. They were then arranged in descending percentage order of the responses each skill received in both groups. Additionally the responses of both groups were compared and statistical significance calculated by using Mann Whitney test on SPSS 10 for Windows.

\section{Results}

Out of 25 questionnaires distributed to the AKU Medical College faculty, 22 were received back, yielding a response rate of $88 \%$. Out of 90 questionnaires distributed to the non-AKU physicians, 57 were returned, giving a response rate of $63 \%$.

The responses of both the groups pertaining to the opinions about the essentiality of the skills were analysed. The responses were divided into four groups, i.e. $76-100 \%, 51-75 \%, 26-50 \%$ and $0-25 \%$. The skills which got approval of $75 \%$ or above participants in both or any of the categories were 
Table 2. Skills marked as essential by at least $75 \%$ members of both AKU and nonAKU Physicians

1. Obtaining blood samples

2. Intra-muscular injections

3. Insertion of nasogastric tube

4. Intra-venous injections

5. Electrocardiography

6. Care of peripheral venous lines

7. Pulse measurement

8. Temperature measurement

9. Intra-dermal injections

10. Subcutaneous injections

11. Insertion of urinary rubber catheter

12. Blood pressure measurement

13. Basic life support

14. Giving oxygen through mask

15. Fundoscopy

16. Nasal speculum examination

17. Insertion of indwelling catheter

18. Dressing in minor burns
19. Preparation of oral rehydration salt

20. Sterile handling of instruments

21. Otoscopy

22. Throat swabs

23. Simple dressing in minor trauma

24. Application of pressure bandage

25. Sponging

26. Pulmonary function tests(interpret)

27. Zeihl Nelson stain (interpret)

28. Pregnancy test (interpret)

29. Care of bedsores

30. Hemostasis procedures

31. Shifting a patient with spinal injury

32. Care of the central venous lines

33. Peripheral film preparation for malarial parasites

34. Urine dipstick (interpret)

Table 3. Skills marked essential by at least $75 \%$ of the non-AKU physicians and not by as many of the AKU faculty. The \% of AKU faculty are given in parentheses

1. Giving blood transfusions $(72.2 \%) \quad$ 8. Establishing central venous lines $(59.1 \%)$

2. Incision \& drainage of an abscess $(68.2 \%)$

3. Suturing of clean wound $(68.2 \%)$

4. Wound debridement (68.2\%)

9. Set up an $\operatorname{ESR}(50.0 \%)$

5. Removing foreign body from external orifices $(63.6 \%)$

6. Preparation of correct strengths of drugs $(68.2 \%)$

7. Interpret Gram stain (59.1\%)

10. Sterile techniques for the preoperative preparation $(72.7 \%)$

11. Insertion of airway suctions (63.6\%)

12. Interpret ESR (72.7\%)

13. Perform urine dipstick $(68.2 \%)$

Table 4. Skills marked as essential by at least $75 \%$ of the AKU faculty and not by as many of the non-AKU physicians. The \% of non-AKU physicians are given in parentheses

1. Stool occult blood (interpret) $(71.9 \%)$ 4. Perform Mantoux Test $(68.4 \%)$

2. Wound swabs $(70.2 \%)$

5. Interpret Mantoux Test (71.9\%)

3. Advanced life support (71.4\%) 
grouped as "essential" skills, from 51-75 \% "important but not essential", 26$50 \%$ as "nice to know" skills and less than $25 \%$ responses as "not required at all". The results are shown in Tables 2, 3 and 4 .

\section{Discussion}

The data analysis of this study reveals that there are more similarities than differences between the opinions in the two groups about the essential skills (Table 2). This highlights the fact that there is an overall consensus among the physicians working in an academic institution and those practicing in the community at the primary care level, about the skills which all the medical graduates must possess irrespective of their future practices. In other areas there were some differences of opinion (Tables 3 and 4) but statistically significant difference ( $p$ less than 0.05) was found in three skills, i.e. setting up and interpretation of Erythrocyte Sedimentation Rate (ESR), incision and drainage of abscesses and giving blood transfusions. These skills were marked more frequently by the primary care physicians as compared to the tertiary care faculty. This may be due to the fact that in a well-equipped tertiary care centre, specialty care is available. The patients may be referred to the surgeons for incision and drainage of abscess, whereas in primary care setups the physicians find themselves in situations in which they have to deal with these conditions themselves. Regarding blood transfusions, the primary care physicians may find it imperative to give blood transfusions in emergent situations. Regarding the issue of setting up of ESR, the physicians in a tertiary care centre do not consider it a specific and helpful test in patient management, but the primary care physicians are still using it as a sole indicator for chronic infectious diseases like tuberculosis, reflecting continuation of old beliefs and practices.

The response rate of the non-AKU physicians was low as compared to the AKU faculty ( $88 \%$ vs. $63 \%$ ). Since educational research is a relatively new concept in Pakistan, the primary care physicians' lack of understanding of the purpose of the study could account for a low response rate from them. It also may be related to the fact that primary care physicians have never been involved by the institutions and credentialing bodies as stakeholders. They may have viewed it suspiciously as an attempt to point fingers at them. The relatively low response rate in the non-AKU group, however, does not appear to affect the results, since in majority of areas the opinions of both the groups are congruent.

\section{Conclusions}

Although the sample size is not very big, the study is a validation study to get an indication of essential skills. Its results may provide a broad perspective of 
required core psychomotor skills for the undergraduate medical curriculum in developing countries like Pakistan. In the next phase other stakeholders, like students, interns and the physicians working at basic health units and secondary health care delivery levels and faculty of other medical colleges, will be involved in identifying essential skills for the undergraduate medical curriculum in Pakistan. Once this is done, it is expected that the faculty and institutions at large will be able to ensure that these skills are mastered by the graduates by the time of graduation. This will insure that medical curriculum is sensitive and responsive to local needs. This will also help in provision of cost effective care to patients near their own localities and decrease the need for referral to the secondary and tertiary care units away from their own homes, which creates various problems at the personal and family level in addition to financial burden.

\section{References}

Cheung, V., Critchley, L.A., Hazlett, C., Wong, E.L. \& OH, T.E. (1993). A survey of undergraduate teaching in anaesthesia. Anaesthesia, 54, 4-12.

CORDEIRO, M.F., JOLLY, B.C. \& DACRE, J.E. (1993). The effect of formal instruction in ophthalmoscopy on medical student performance. Medical Teacher, 15, 321-325.

DAVID, S.S., SELVARANJinI, S. \& THOMAS, M. (1997). Incorporation of emergency medicine in the undergraduate curriculum. National Medical Journal of India, 10, 8081.

IRby, D.M., LIPPERT III, F.G. \& SchAAD, D.C. (1991). Psychomotor skills for the general professional education of the physician. Teaching and Learning in Medicine, $3,2-5$.

Jansen, J.J., Grol, R.P., Van-Der-Vleuten, C.P., Scherpbier, A.J., Crebolder, H.F. \& RETHANS, J.J. (2000). Effect of a short skills training course on competence and performance in general practice. Medical Education, 34, 66-71.

LeVenthal, W.D. \& GoOdman, B.W. (1981). A curriculum in practical clinical skills for family medicine residents. Journal of Family Practice, 13, 889-891.

NoOMAN, Z.M. (1989). Implementation of a community-oriented education. The task and the Problems. In: H.J. Schmidt, M. Lipkin, M.D. de Vries Jr.\& J.M. Greep (Eds.), New Directions for Medical Education, Problem Based learning and CommunityOriented Education. New York: Springer-Verlag.

Ringsted, C, Schroeder, T.V., Henriksen, J, RAmsing, B, Lyngdorf, P, Jonsson, V. \& SCHERPBIER, A. (2001). Medical students' experience in practical skills is far from stakeholders' expectations. Medical Teacher, 23, 412-416.

SnOw, N. \& ImBEmbO, A.L. (1986). Thoracic surgical content of an undergraduate surgical curriculum. Surgery, 100, 83-88.

STURMBERG, J.P. (1995). Procedural skills in general practice: Are we going to lose this facet of general practice care? Australian Family Physician, 28, 1211.

World Health ORGanization (1997). Tuberculosis control and Medical Schools. (Workshop report). Italy: World Health Organization.

Woodcock, T. (1995). Clinical skills still provoke debate. Clinical skills are complemented by technology [letter; comment]. British Medical Journal, 310, 1281. 